\title{
VOCATIONALIZING EVENT MANAGEMENT DEGREES
}

\author{
WENDY SEALY \\ University of Chichester, Bognor Regis Campus, West Sussex, UK
}

\begin{abstract}
This article evaluates an approach to teaching and assessment that deviates from the norm in higher education. It assesses graduating students' experiences with the BA (Hons) Event Management degree at a post-1992 university in the UK. Instead of writing a thesis, students stage a complex but sophisticated live event as partial fulfilment for their honors degree. The methodology was underpinned by an interpretivist philosophy with three graduating cohorts of 2012/13/14 participating in the research. The findings highlighted positive outcomes related to skills development and wider operational issues that affected student learning. The majority of students were satisfied with the overall degree outcomes but anxiety and fear about the assessment objectives, client idiosyncrasies, and demands; and, the fact that event management is hard work was perceived negatively by some students and as flaws with the university and client organizations. The findings precipitated changes to how students are supported on live event projects and to the collaborative relationships between clients and the university.
\end{abstract}

Key words: Experiential learning; Event management; Live event assessments; Vocational degrees

\section{Introduction}

The transformation of higher education (HE) institutions from elite to mass provision in the UK has precipitated a cultural shift in the design of the curriculum towards more vocationally oriented subjects to satisfy the mandate of policy makers for more commercially aware graduates. This article presents an ethnographic reflection on student and lecturer experiences with a semivocational degree in event management at a post-1992 university located in a very peripheral and insular region of the UK. The event management degree at this modern university represents a major innovation in $\mathrm{HE}$ where an experiential approach to pedagogy has been adopted with students delivering "live" event projects for "real" clients instead of writing a thesis in their final year. Experiential approaches to learning and teaching, otherwise known as "work integrated learning” (Jackson, 2013), aims to bridge the gap between classroom theoretically based concepts and professional practice by allowing students to apply their classroom acquired knowledge on real life cases. The experiential approach that is 
the focus of this study involves students collaborating with a local business/charity to deliver a complex event project aimed at achieving the corporate aims and objectives of the partner organization.

Industrial shifts towards the service economy, technological change, computerization, complex communication systems coupled with changes in managerial hierarchical structures in favor of teamwork and multitasking have increased the demand for workers with out-of-the-box thinking, human interaction skills, and digital literacy (also see Garlick, 2014; Tsai, 2013). Consequently, employers are now more likely to select graduates based on skills and attributes developed through their studies; particularly the "transferable" skills, otherwise called "core skills," "generic skills," or "soft skills" that can translate into a competitive advantage for the company or organization that hires them. Employers want graduates with well-developed generic skills (Pool \& Sewell, 2007) that will enable them to transition into the very competitive commercial world.

Higher educational institutions have responded by embedding experiential pedagogic initiatives including placements, internships, and other practicums into the curriculum. Experiential learning moves the learner away from passive transmissionreception forms of learning to a more participative application and integration of knowledge and skills. Seminal author Kolb's (1984) model of experiential learning suggested that experience with subsequent reflection enables students to better apply classroom theory to industry practice. Several studies have reported on the positive outcomes of placements, internships, and other forms of workbased learning inside professional organizations for event, hospitality, and tourism students (Beattie, Nixon \& Walker, 2008; Fletcher-Brown, Knibbs, \& Middleton, 2015; Fox \& Morrison, 2010; Hingley, 2008; Nixon \& Dray, 2010; Robertson, Junek, \& Lockstone-Binney, 2012; Sealy, 2012). Employers place significant value on vocational experience with project management, working with audiences and customers, hands-on production experience, budgeting, fundraising, and marketing planning being highly desirable (Beaven \& Wright, 2006).

Experiential learning provides benefits that extend beyond the development of soft skills and knowledge. Along with adding value to a $\mathrm{CV}$, some studies note that graduates become more commercially aware or more confident individuals because of their placement or internship (Fletcher-Brown et al., 2015; Fox \& Morrison, 2011). Indeed, an internship/placement within a well-established organization exposes students to industry professionals, etiquette, manners, maturity, and best practices. Exposure to organizational culture and a better understanding of how organizations function are some of the key benefits of working in collaboration with industry professionals. Alongside the traditional internship and placement models of experiential learning, other work-based experiences such as a practicals, consultancy projects, shadowing programs, and immersion projects, all with distinct outcomes for learning (Hughes, Mylonas, \& Beckendorff, 2013), are common in hospitality and event management education. The recent popularity of event management degrees in the UK has seen the emergence of other forms of experiential learning known as the "live event" project with students staging real events in collaboration with a business. Researchers report positive benefits for students on live event projects and suggest that the positive outcomes far outweigh any human, logistical, or operational difficulties that result from the collaborative nature of the projects (Fox \& Morrison, 2010). However, due to the embryonic nature of event management as an academic discipline there is still a dearth of research in this aspect of experiential learning.

The extent to which universities can produce employable graduates depends on the students' willingness to engage in paid or unpaid work during their studies and the extent to which the corporate sector is willing or able to provide suitable projects and other opportunities through placements, internships, live events, or volunteer work. The fact is, the trajectory into employment is very complex and several intervening factors including the individuals' willingness to make an impact and to take advantage of, and identify, opportunities; their attitude and other personality traits will have an impact on how well they achieve their immediate and long-term career goals. Nevertheless, event management graduates who are capable of assessing, designing, planning, delivering, and evaluating events of all types as well as "custom designing highly targeted event experiences” (Getz, 2008, 
p. 121) to achieve the client aims and objectives may achieve an advantage in the labor marketplace as highly employable individuals.

\section{Event Management Degree at} the Post-1992 University

EMBOK (Event Management body of knowledge) provides a repository of knowledge for event management, which is rooted in business management, encompassing administration, design, marketing, operations, and risk management (Table 1).

Although EMBOK is very thorough in identifying a range of knowledge-based disciplines to support the industry, event management is also a very applied "hands on" profession requiring skills that cannot be taught by a transmission-reception model of learning and teaching. The problem with EMBOK is that it does not accommodate these transferable skills or soft skills that employers presumably want. Soft skills like attention to detail, listening, negotiation, personal selling, high-level cognitive skills, problem solving, emotional intelligence, pitching, time management, and leadership are developed through practice rather than from a textbook. Consequently, to gain a competitive advantage and to attract nontraditional learners, particularly those with visual and kinesthetic modalities, the event degree at this post-1992 university marries a strong vocational dimension with academic acumen.

At levels four and five (4/5) students are introduced to the main concepts and theories in organizational management, marketing, finance, event design and creation, and business decision making. The major experiential component of the degree occurs in the final year when students have the opportunity to apply theory to practice through the execution of a real "live" event management project. The module Applied Event Management 1, 2, and 3 require students to deliver a sophisticated yet complex event at a venue outside the university, which replaces the traditional thesis. To ensure that the projects meet the needs of the industry it is important to involve industry professionals in the students' development (Lee, Lee, \& Kim, 2009) and thus suitable organizations from the charity and business sectors "act" as clients. Client-driven projects offer students experience in managing the

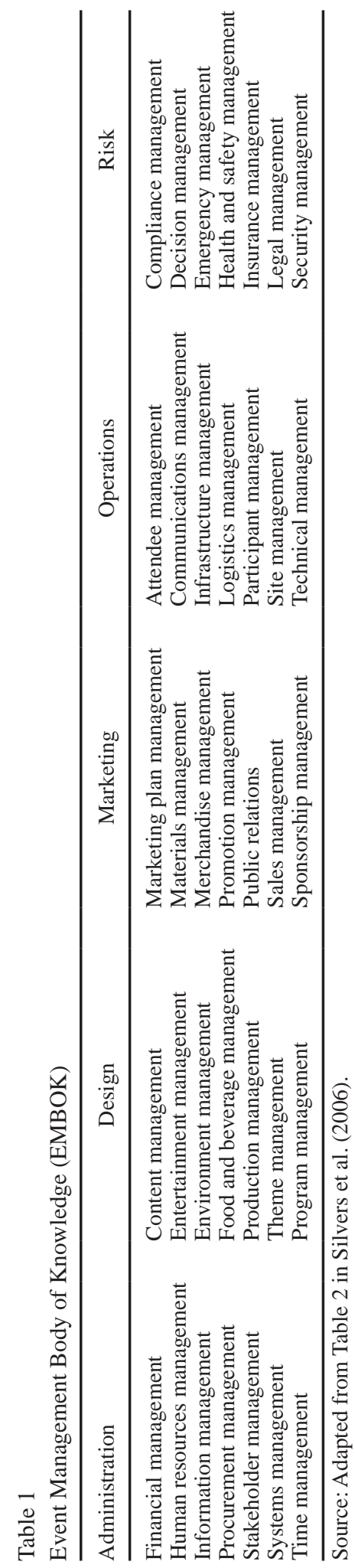


vagaries of the event environment, client exigencies, and engages them in strategic thinking, flexibility, and negotiation similar to what they would experience when they embark on their careers. In an effort to promote "deep" rather than "surface" learning and to challenge students outside of their "comfort zone," clients present students with a business problem and clearly defined business objectives, which the students must achieve through the design and delivery of the "live" event.

The module adopts the coconstructivist approach to teaching and learning with students collaborating to solve a real business problem. The students collaborate, working in small groups of 6-8 students in order to ensure that the multiplicity of tasks and skills required to complete the project are realized. To address the client brief, students are required to engage in a critical investigation involving the reconstruction of earlier knowledge as they evaluate, analyze, define, and interpret the requirements of the brief in order to meet client needs and expectations. After the initial assessment, students are required to propose suitable events that resonate with the clients' brand and organizational goals. To ensure that the work environment is as close as possible to reality, students plan and deliver these events in an environment that is "organic" and intervention on the part of the university only occurred in cases where a client had concerns about reputation, health and safety, or corporate liability. Weekly tutorials with tutors provide guidance and support for the students for the duration of the project.

\section{Methodology}

This reflection is specifically directed towards the graduating classes of 2012/2013 and 2014 in event management who at the time of data collection in week 14 are assumed to be better positioned to reflect holistically and objectively on their university experience having completed the 3 years of study.

Modeled from ethnography, the process of reflection is now a well-established practice in professional education (Harrison, 2010). As a relative of phenomenology, ethnography is a form of storytelling from the perspective of those being studied in order to understand their perceptions of an experience. Reflective practice is the integration of knowledge to comprehend important processes within the teaching profession and to reflect on how these processes can be integrated or modified for the best possible outcomes. Reflective practice, combined with other qualitative research methods, is widely used in ethnographic studies, particularly those areas involving social action (Bowen, 2002; Sealy \& Wickens, 2008; Wickens, 2002).

With ethnography and reflective practice being the underlying principle behind this article an eclectic approach to data collection was undertaken resulting in a triangulation of data from a purposive sample of three graduating cohorts and the researcher's observation log and literature review. The strength with purposive sampling is that it enables the researcher to select "information rich" cases to be studied. Information rich cases are those from which a great deal can be learned about issues that are of central importance to the purpose of the research (Patton, 1990). Based on semistructured focus group interviews with event students, the data yielded lengthy transcripts that were analyzed and collated into themes. It is noted that student feedback is only a snapshot of student opinion and that its real value lies in its use in longitudinal studies (Brooks, 2003). With this in mind focus groups were held at the end of semester two of 2012, 2013, and 2014 (Table 2), 2 weeks after the students had completed all of their course work as it was felt that students would have had time to reflect on their learning and achievements and would be in a more relaxed frame of mind to provide constructive feedback on their course of study (Hounsell, 2003).

The data were analyzed using the coding procedures suggested by Strauss and Corbin's (1990) grounded theory. Open coding was used to identify categories, concepts, and themes without making any prior assumptions about what might be discovered. The data were broken down into discrete parts, closely examined, compared for similarities and differences, and questions asked about the phenomena being studied (Strauss \& Corbin, 1990). After the preliminary coding process, a further coding system was employed where codes were related to each other through the identification of core code categories and subcategories, which were then organized and collated into themes and subthemes (Hammersley \& Atkinson, 1995; Robson, 1993). 
Table 2

Schedule of Focus Groups

\begin{tabular}{lccc}
\hline Year of Focus Groups & Total Responses & Total Enrolment & Number of Focus Groups \\
\hline April 2012 & 22 & 36 & 4 \\
May 2013 & 24 & 32 & 4 \\
May 2014 & 12 & 14 & 2 \\
\hline
\end{tabular}

A synthesis of the major themes that emerged is presented below.

\section{Student Experiences With the Vocational Degree}

The forthcoming discussion focuses on the reoccurring themes that emerged from the focus groups with the three graduating cohorts. This section integrates these findings with practitioner reflections to provide rich and illuminating narratives on the student experience.

Students were of the view that the degree delivered over and above their expectations in terms of the final outcome-a successful event that met client specifications, objectives, learning outcomes, and a job interview. Many appreciated that the level six live projects gave them an opportunity to gain a realistic perspective of the industry and to experience the responsibilities and the challenges of working in a commercial environment, which equipped them with the confidence to foray in their chosen profession. As this student reiterates:

My University also gave me the opportunity to create, design and plan entire events and I believe the lessons I learned are invaluable. I have come to the end of my degree and feel completely confident about entering the events industry.

Some students felt that the business focus was a distinct advantage of the course as exemplified by the comment: "I believe the skills and attributes I now possess could enable me to excel in . . . corporate events; as this is where my strong business mind such as finance could shine through."

With linear career progression throughout one organization becoming extinct (Bridgestock, 2009) it was important that students recognized that the "added value" in their newfound skills is that they are transferable to industry sectors outside of event management. This was evident from the focus groups as exemplified by this student and was one of the learning outcomes on the module: "This degree has set me up to qualify for a multitude of different jobs in various industry sectors." There is an increasing need for flexible, adaptive, and industry mobile workers who can integrate, adapt, and utilize their skills to a multitude of different jobs, tasks, industries, and cultures as their professional circumstances require and it was important that through experiential learning students came to this reality (Bridgestock, 2009; Harvey, 2005).

The introduction of the client provided an opportunity for students to understand the dynamics of interpersonal communications in a large organization and to learn the terminology, parlance, jargon, and linguistic style of the industry. It is important for students to understand that organizations have different cultures and being employable relates to being able to adapt skills to cross professional, social, and cultural environments (Fox \& Morrison, 2010). Students were able to develop their communications skills and learn how to behave professionally through formal interactions with the client and suppliers in meetings or through written business communications; and, be able to adjust their communication techniques depending on the receiver. Through involvement and engagement with clients, students were able to appreciate the multiple, complex, and strategic functions that events play in business and the community, which helped to dispel the earlier cognitive dissonance students experience at the beginning of the course in relation to the strong business subject focus. As this student pointed out: "I thought that we would just book a band and rent a tent and we would have an event. Now I know that this was naïve."

Due to the different roles and responsibilities associated with delivering "live" events students used the opportunity to specialize and develop a particular area of expertise. Others thought that the 
degree helped them to identify personal strengths and weaknesses.

After organising the legal aspects of ... and being the health and safety/legal . . . I now feel that this is one of my main strengths and is something that I may consider focusing on when I graduate from university.

Being able to reflect on their experience students were able to identify gaps in their learning and to identify specific skills that had evolved or were enhanced due to the projects without being prompted by the researcher. Table 3 articulates the "transformational epiphanies" that occurred as students reflected on their learning. Transformational epiphanies, which emerged through reflection, are learning curves that totally transform the way individuals view the world, themselves as members of society, and the way they think. This was encouraging for module tutors as reflection is what changes a mere experience into a learning exercise (Robertson et al., 2012). As shown in Table 3 the transformational epiphanies are manifested as skills and aptitudes discovered by students through reflection. These emerged from four distinct dimensions: self-awareness and meta-cognition, practical skills, commercial awareness, and relationship management.

The epiphanies were then transformed into a prototype of the EMBOK model, which goes beyond the knowledge disciplines to provide an emergent event management body of skills for the event sector (EMBOS). As shown above, through reflection the students were able to identify the skills that they used to complete the projects by assigning their own meanings to the epiphanies, which emerged. This self-discovered knowledge demonstrates that with experiential learning projects tutors do not have to be concerned with "putting in" knowledge as with the transmission-reception model of teaching but should be more concerned with "drawing out" the new knowledge that surfaced naturally from the projects (Carnell \& Lodge, 2002). With experiential learning students were able to move away from an epistemological concept of knowledge as uncontested facts and instead started to view knowledge more in line with situational context and individual experience as they drew close to the conclusion of their projects. Students noted how their perceptions had changed as a result of their new knowledge and that they had become different persons as they transformed from event students to event professionals. As one of them stated, "I am now more forward thinking."

The fact that students were able to identify a range of skills personal to them demonstrates the value of live events in stimulating meta-cognition and greater self and environmental awareness. Meta-cognition is the ability to reflect on problems and challenges and make sense of them. It empowers students to reflect on strategic decisions, problem solving, and the challenges of working in a real organization. With live event projects students can make their own mistakes and learn from

Table 3

Event Management Body of Skills (EMBOS)

\begin{tabular}{llll}
\hline Self-Awareness/Metacognition & \multicolumn{1}{c}{ Practical Skills } & Commercial Awareness & Relationship Management \\
\hline Confidence & Communication skills & Enterprise & Teamwork \\
Forward thinking & Transferable skills & Entrepreneurial spirit & Client management \\
Recognition of learning styles & Career management & Competition & Stakeholder management \\
Self-efficacy & Presentation skills/pitching & & Flexibility \\
Imagination & Stress management & Negotiation \\
Creativity & Decision making & Delegation \\
Emotional intelligence & Negotiation & Conflict management \\
Cognition & Public speaking & Diplomacy \\
Pedagogy & Consultancy & \\
Assertion & Problem solving & & \\
& Organizational skills & & \\
& Analytical skills & & \\
\hline
\end{tabular}

Source: Author's research. 
them through reflection. As students become aware of how theory informs practice they can use their experience as exemplars in interviews with prospective employers (Graham, 2003; N. Jackson, 2010). Through active participation, self-generated knowledge can be a powerful tool in building selfconfidence, self-assurance, emotional intelligence, social awareness, and a sense of accomplishment, which is crucial for employability. Experiential learning is very student centered, requiring students to actively participate and take responsibility for their success or failures. They can draw conclusions and use their conclusions to inform future experiences.

It is at this juncture of self-discovery that students became more receptive to what was being taught to them on the course. It became clear that once the perceived threats to success were removed and the objectives or financial targets that were part of the brief were about to be realized students became more receptive to learning and felt more positive about their course of study. It appears as through learning for students in event management proceeds if the perceived social and emotional risk to the self is low or is removed. Drawing close to the completion of projects when students realized that their events could be successful their attitudes and perceptions changed about the course, university, and events industry. At this juncture, students were also getting interviews for jobs and receiving feedback from employers about their event course. Some students commented that they already had job offers while others used their event as part of a job interview by inviting the prospective employer to see her/his capabilities first hand. The live events were instrumental in helping students to develop their employability portfolios and students are encouraged to take photographs and to video tape their events to present to employers as is done in the field of entertainment. Another took advantage of their client's extensive network of contacts to learn more about the industry by shadowing someone from their organization once a week to gain more insights into management and organizational culture. Although pedagogic success was evident from the live events, there were also several operational difficulties that threw a shadow over the students' experience and highlighted several risks that had to be overcome.
The involvement of clients presented risks to the university and many challenges for these students. Students were keen to expound on this aspect of the project claiming that clients were not always supportive or good examples of best practices. Some clients had ideas about what constituted a wellmanaged event, which contradicted what they learned on the course. Some clients had standard operating procedures that deviated from that of the university, particularly about health and safety management that raised issues of corporate liability. The "student" label meant that some clients had no faith in the students' abilities and one group reported how a client made derogatory and demeaning comments to them in front of suppliers. Another group felt that their client lacked knowledge of event management and that their ideas for the event were unrealistic and illegal. Others complained that clients were verbally abusive and withheld information and resources that were vital to completing the projects and the associated assessments. According to this group of graduates, something as simple as the decision to get qualified security, a legal requirement, at their event "was one that we had to push for." One group of students asked to change their client as they felt that "the client was expecting them to plan the event in an unprofessional, illegal, and unrealistic manner.” Another client cancelled a project midway in the academic year claiming that they were no longer able to fund the event and took the venue with them.

Some students commented about clients being demanding and treating them as though they were a hired labor force. As this student noted: "They are behaving as though they are paying us. ... We should be able to do things in our own time." Some students claimed that they found it difficult to communicate with their client because of social class differences. Others lamented about clients' tendency to withhold payment to suppliers and quivering over the reimbursement of "out of pocket" expenses incurred by students even though the terms and conditions regarding these aspects were clearly outlined in the agreement signed by the students, university, and client. Students felt that they could have been given more training and warnings about the dynamics of client relationships: "we have never experienced working for a client before. We should have been warned about how clients 
behave," one student lamented. Some clients were consistently delinquent when it came to answering e-mails while others withdrew resources and support. Students were quick to point out that they felt that the client projects could have been better organized, and that the university should have screened the clients better.

This experiential exercise bought about the realization that responsibility, accountability, and meeting deadlines were the reality of the "real world." For the module tutor this was particularly welcomed because many students enter the degree program with unrealistic notions of the profession and very limited career awareness. Those who investigated the profession before embarking on HE did not necessarily obtain information from professional bodies, universities, or statutory providers of employment (Donnan \& Carthy, 2011) but depended on peers or social media (word of mouth), press reports, or a vicarious experience with event management in school. There is an ongoing issue about the reality mismatch between the expectations of students entering higher education and the needs of the professional sector (Wickens \& Forbes, 2004; Sealy, 2012). As this student stated: "I imagined myself floating around in a ball gown welcoming guests as the event unfolded. I know now this was unrealistic." Some students felt that the staging of live events was very difficult and that the marking criteria were unrealistic. Several students alluded that the demands of the clients, the district council, and venue managers, on top of the challenges encountered selling sponsorship, tickets, and advertising space was too much for undergraduates to bear. A simple request from a client for a $2.5 \%$ return on their investment and a financial plan with a stated breakeven point was deemed unreasonable and annoyed some students. The performance-related goals are a reality of the workplace and is connected to job targets that link to corporate objectives, thus the justification for their inclusion in the client brief. Students reaction to the request for a breakeven analysis was seen as "irrelevant ... . it is fresher's stuff” referring to it being covered in the 1st year of the degree. These complaints bought tutors to the realization that students tend to compartmentalize their knowledge by storing it away to be forgotten and were not receptive to retrieving it for professional practice. This is an impact of the ubiquitous modularity of knowledge bought about by the semester system where once the module is completed the knowledge is filed and stored for good. Consequently, some earlier concepts had to be revisited in the tutorials.

Early in the projects students experienced trepidation about the demands of the client, the objectives, and the amount of work involved because they felt that the objectives and projects were unachievable. Some students' early skepticism about the course content and their misguided notions about the nature of the industry created a belief that the performance targets were unrealistic resulting in some students rebuking the assessment brief and subsequently, along with their parents, insisting that the assessment be reviewed. These disputes make a mockery of the higher education system as performance related targets are a reality of the workplace and are often used in employee performance evaluations. These events raise questions about the student as customer, rather than learner, bought about by the fee-paying regime and its negative impact on academic quality standards. Students' early resistance to live events, as an innovative and discursive form of assessment, and the ensuing complaints justifies tutors' preference for didactic styles of teaching in favor of the traditional thesis. Tutors become reluctant to challenge students outside their comfort zone for their academic and personal development for fear that it would bring forth negative module evaluations or poor National Students' Survey (NSS) scores (O’Donovan, 2010).

Some of the difficulties encountered by students on their projects were simply reflections of the vagaries, exigencies, and unpredictability of the event and commercial environment. Students' inability to apply theory and their lack of knowledge and understanding of the way the work place operates exacerbated the situation. However, rather than view these challenges as opportunities for growth and development some students perceived these difficulties as a negative reflection on the university and client organization. Those who expressed this view felt that the projects could have been better organized and that they could have been better supported by the academic staff. Some felt that the client's role could have been more engaging and supportive, and that the client could have done some of the work including providing them with business contacts, 
finding sponsorship, or selling tickets. Some felt that the client and university had too much control over the event and that students should be able to set out their own aims and objectives. As stated by this student: "From my experience I can see that the aims set for our live event were unrealistic and if there had been more control over what the live event could have been it would have been more beneficial for learning." Some felt that working to client specification prevented them from unleashing their creativity and stifled innovation. This was unfortunate as artistic expression and creativity are regarded as essential for event managers and it was the intention of tutors to allow students to explore these attributes through the live projects (Silvers, Bowden, O’Toole, \& Nelson, 2006). Others commented about the time needed to complete the projects, which also fell outside work hours and class time. Others described the overall experience as "confusing" and "frustrating" as clients failed to acknowledge the limitations of the academic cycle and other resource limitations, like student capabilities or funding and legal restrictions. The realization that most of the work in event management is administrative and that the management of clients, stakeholders, and suppliers could be challenging was a "bitter pill to swallow" for some students. Having to deal with demanding clients or abusive suppliers bought students to the realization that the event environment could be just as hostile as it is competitive. As one student explained: "The event industry is not enjoyable like I expected . . . it is not glamorous at all, in fact, it's more like organized chaos and stress." These comments illustrate the sometimes-significant differences between student expectations, perceptions, and the realities of the workplace, leading them to believe that something is wrong with the educational institution (Bennett \& Kottasz, 2006). Some students had to be referred to student support for psychological counseling during the period leading up to the delivery of their projects.

Some students encountering challenges on live projects reacted on social media and on the NSS rather than seek help from tutors. It is understandable that students would feel overwhelmed by the projects, particularly those with no work experience. Other students noted that the level of stress involved in planning an event was overwhelming.
When weaker students were asked to think problems through using problem solving tools this was perceived as flaws with the university's learning and teaching strategy rather than the need to assess, review, and change their strategies. What was clearly apparent is that the traditional idea of reading for a degree was replaced by the expectation that the tutor would tell them exactly what to do and present a magical formula that would enable them to pass the assessment (Wickens \& Forbes, 2004). Some students appeared to prefer the passive transmission/reception mode of course delivery although this method does not stimulate the cognitive processes that would enable them to apply and make sense of their theoretical knowledge in the complex business world and certainly does not facilitate independent learning (Carnell \& Lodge, 2002). It was evident that the live projects were more beneficial in terms of students' long-term employability skills, but some did not like it (Kolb \& Kolb, 2005; Penger, Znidarsic, \& Dimovski, 2010; Stevenson, 2004).

\section{Discussion and Recommendations}

It was evident that the transition from student life to work can be quite traumatic and represents a quantum leap in learning for some individuals. Some students did not appreciate the amount of work that had to be completed or the difficulties they encountered "on the job." It was clear that along with logistical and human difficulties students, particularly the weaker ones needed a "helping hand" with client relations. Tutorials on client management and organizational culture have been introduced so that students identify and understand the different ways clients may behave during their event and after graduation. Additional training for students in conflict management, business etiquette, cultural leadership, and communications assist in preparing students for projects. Over the years there was an appreciation that event management is "work" but some students continue to feel that the difficulties of their projects could be circumvented through better organization or "more realistic" goal setting by university staff. Employer forums where students can pose questions to current practitioners about their projects have helped to make students feel more supported and to reinforce the 
view that the projects are achievable. Employers can reassure students that their projects are realistic and deliverable and that the skills developed are marketable. The voice of industry practitioners is viewed as authority by students as they are directly involved with the industry. Students' misguided notions about the nature of the event management industry were often a key influence on their attitude towards certain experiential tasks, often producing an apathetic approach to learning. Consequently, an accelerated campaign to encourage students to go out on professional placements has been initiated.

Consternation bought about by the inclusion of performance-related targets in the event brief bought tutors to the realization that work needed to be done to inspire students to accept learning challenges as part of their development. Seminars that ensure students understand the rationale behind the assessment pedagogies and program structure may make students more "pedagogically intelligent" and aware of how these targets relate to industry practice, how they learn, and their learning styles. Students need to be encouraged to embrace assessment challenges as opportunities for growth and development rather than to view them as threats. It was essential that students recognized that skills development did not occur overnight but is a gradual process that takes place over several years. Students need to be reminded constantly and consistently about the intended learning outcomes of the module, why they are important, and how they link with industry needs. They need to understand that the degree is designed to take them beyond entry level jobs into management and that they should set higher goals and aspirations for themselves while acknowledging the different career route possibilities in event management.

The transformational epiphanies that emerged from the projects always brought forth feelings of gratification and self-actualization, which made students receptive to learning and it was important to maintain such levels of gratification throughout the entire course of the projects rather than just at the end. Consequently, reflection and subsequent goal setting is now a weekly exercise in the tutorials when students spend time reflecting on their learning curves through acknowledgement of their recent triumphs and successes and how they can add value to employers for inclusion in their CVs.
Students may commit to learning if the pedagogic initiatives are realistic to them and merits application in the real world. As Biggs and Tang (2007) noted, motivation for learning arises when something has value to the student and they expect success from their endeavors. Pedagogic literacy may help to dispel some of the distress that students experience because of the live event assessment brief. Millennial learners must be heavily supported, inspired, motivated, guided, and encouraged to challenge themselves, to take their learning to a deeper level, to reflect often, and to develop their own abstract concepts and contextualize their learning from concrete experience and subsequent reflection (Kolb, 1984).

It is clear that the introduction of a client-aided student learning significantly but at the same time this initiative represented a major risk to the student's degree, final grade, and the university's reputation, and resulted in a distillation of the university-student-client relationship. To ensure that clients do not put the student's degree at risk the university had to assume ownership and funding of the live events, which is now clearly stated in the agreement with clients. Clients are now beneficiaries of fundraising and mentors to students rather than investors and are asked to be more sensitive, supportive, and gentler in their interaction with them. It had to be made clear to clients that participation in live projects with students did not guarantee that the event would raise funds and that they should not include the projected fundraising into any financial projections. This approach has worked well for maintaining better community relations and for reducing the earlier conflicts that occurred between the trilogy of stakeholders: client, student, and tutor.

Collaborating with employers and other community groups to facilitate student learning has its benefits for the university. The benefits of positive press coverage that raised the image of the university in the local community were certainly welcomed. The opportunities for knowledge exchange and networking can be invaluable to students and faculty. Although it is important to engage with industry on live event projects this needs to be done in a systematic manner based on academic and pedagogic underpinnings in order to ensure that the appropriate mix of skills emerge from the 
projects and that the methodologies used to deliver the projects are based on event industry best practices that are academically sound. However, finding suitable clients for event management projects is an ongoing challenge due to the dearth of professional organizations in the immediate region. The event management profession is still an emerging one and many event organizers are self-taught freelancers. Such practitioners, although lauded for their excellent work, did not necessarily undertake theoretical studies in event management and at times could not relate to the models students used to plan their events. At times this caused confusion and conflict between students, tutors, and the client organization. The multiple and complex nature of events coupled with conflicting stakeholder agendas has prevented the introduction of standardized practices and methodologies that are universally recognized resulting in differences in the standard operating procedures used by students, tutors, and clients. Unlike the more cosmopolitan areas, many corporate organizations or charities in this very peripheral region fall under the small to medium-sized business profile where practitioners are sometimes the "Jack of all trades" and "masters of none.” As Goldblatt (2000) highlighted, the rapid growth of the event profession has produced a climate that is confusing and lacking in credibility when compared to other professions, probably due to the apparent lack of regulatory bodies for the mandatory licensing and credentialing of event practitioners. These realities make it difficult to find professional clients who are good examples of professional practice instead of those who insist on unsystematic, archaic, or unsophisticated ways of organizing events. These issues bought tutors to the realization that this state of unconscious incompetence is the foundation for poor planning and decision making that is synonymous with the event profession (Getz, 2008; Silvers et al., 2006). Due to the island mentality that pervades the region, it is very difficult to encourage continued professional development among industry leaders. In order for experiential learning to be truly effective the live projects must be a true reflection of the work place; but, the involvement of real clients presented anxiety, trepidation, and significant risks for the students and university and had to be discontinued in its original form.
The development of an emergent EMBOS for event management illustrates the value of live events in harnessing the critical skills required by event managers and highlights the range of skills and competencies that are required to deliver sophisticated and complex projects. EMBOS can be used to inform educators and employer collaborators in event education regarding appropriate assessment design. EMBOS can also help negotiations with employers regarding the criteria for mentoring event students through their work-based projects. Employers must have a genuine desire to be part of a collaborative partnership that puts the students "first" and should be less prescriptive but more committed to giving the students the freedom to organize events that explore a range of skills and opportunities. EMBOS can be seen as a new protocol and robust body of evidence that facilitates a framework for HE assessment design methodology that justifies the event management curriculum. Sitting alongside EMBOK, it also illuminates and enhances our understanding of the event profession and the organization of curriculum to teach it.

\section{Concluding Remarks}

Students embarking on this degree did not anticipate that the planning of major events could be challenging, and the management of suppliers, clients, and peers could be overwhelmingly stressful highlighting the need for more systematic and focused support for students on live projects. However, the projects were instrumental in building confidence and self-efficacy, which played a part in preparing students psychologically for the world of work. The role of the projects in the development of higher self-esteem and in creating high levels of gratification and student satisfaction cannot be discounted and brought forth a $97 \%$ overall satisfaction rating on the NSS in 2016 after all of the recommendations above were implemented.

A single encounter with one organization should not be construed as an initiative that will necessarily transform individuals into efficient and capable workers. What the projects did achieve was to make students more aware of the commercial environment and the skills and knowledge that they must develop if they wish to have a successful career. It could be years after graduation before 
a student develops expertise in their chosen field and the value of a degree is realized in terms of earnings and career prospects. The realization that event management consist of mainly administrative work, as exemplified by the mountains of paperwork produced by the projects, should be a concern for educators. It could be argued that the vocationalization of event degrees promotes the development of technocrats instead of critical thinkers. The need to be "industry relevant" has reinforced students' tendencies and preferences for didactic teaching to avoid pursuing in-depth and abstract knowledge and theorizing. The danger with this is that it develops graduates with a lack of theoretical and conceptual expertise, tunnel vision, and a lack of appreciation for the wider strategic, historical, social, economic, and political context that events play in the wider community and business sectors. Although the live projects did produce "able bodied" "can do" graduates, they did little for the students' intellectual development and robbed them of the opportunity to develop in-depth theoretical and strategic knowledge of the sector, highlighting an inherent trade off that comes from not writing a thesis. There is a growing consensus that the ceding of work-based training to universities as though they were labor factories is undermining the higher education curriculum (O’Donovan, 2010; Sealy, 2012; Wickens \& Forbes, 2004). Although live projects, over the years, did bring forth high levels of student satisfaction on completion, high levels of student satisfaction may be a red flag signaling the existence of poor academic standards within the institution, a consequence of the commoditization of higher education to appease the new nontraditional student regime (also see Temple, Callender, Grove, \& Kersh, 2016).

Live events need to be supplemented with other work-based learning, including professional placements, internships, and volunteer work that would enable students to work alongside and learn from professionals in a corporate environment. However, engaging time-poor students in extracurriculum activities like volunteer work to broaden their horizons and to expose them to professional practice early in the course continues to be an ongoing challenge sector wide (Nixon \& Dray, 2010; Sealy, 2012). The extent to which "live events" can help advance a graduate's career into senior management still needs to be fully researched. There is a need for greater saliency concerning the employability requirements of employers for event management graduates. It is not clear if there are distinctions between the requirements of small to medium-sized and large enterprises, between local, regional, national, and international organizations, or between event subsectors.

In reflection, the execution of live event client projects for developing professional standards can be extremely labor intensive for tutors who end up managing the students' coursework, group dynamics, their expectations, and idiosyncrasies, and then in turn have to do the same with the client and other stakeholders. Significant pressure on the tutors to ensure a safe event adds trepidation. This method of teaching requires a significant commitment on the part of the students and staff, often requiring staff to work outside of contract hours and students giving up time spent with family and in paid work. This research has presented a cogent discussion on a single case of experiential learning in event management at a post-1992 university in the UK and is not intended to be transferable to other educational or institutional contexts. It is perhaps axiomatic, but worth mentioning, that further research is required in cross-institutional, educational, and industrial contexts in order to further advance our understanding of experiential learning for event management and other business subjects; and, to establish a practical, relevant, and coherent model for experiential learning in event education. The study illustrates the value of the "student voice" in participative decision making, contributed to an emergent EMBOS for event management and highlighted contextualized areas in learning and teaching that warrant further research and consideration. It represents the subjective experiences, beliefs, feelings, and attitudes of the event students, lecturer, and tutors who were the subject of the investigation.

\section{References}

Beattie, I., Nixon, S., \& Walker, C (2008). From potential to achievement: Enhancing students' value to employees. In S. Graves \& A. Maher (Eds.), Developing graduate employability: Case studies in hospitality, leisure, sport and tourism (pp. 1-16). London, UK: Threshold Press Ltd. 
Beaven, Z., \& Wright, R. (2006). Experience, experience, experience! Employer attitudes to arts and event management graduate employability. International Journal of Event Management Research, 2(1), 17-24.

Bennett R., \& Kottasz, R. (2006). Widening participation and student expectations of higher education. International Journal of Management Education, 5(2), 47-65.

Biggs, J., \& Tang, C, (2007). Teaching for quality learning at university. London, UK: McGraw-Hill Education.

Bowen, D. (2002). Research through participant observation in tourism: A creative solution to the measurement of consumer satisfaction/dissatisfaction (CSID) among tourists. Journal of Travel Research, 41, 4-14.

Bridgestock, R. (2009). The graduate attributes we've overlooked: Enhancing graduate employability through career management skills. Higher Education Research and Development, 28(1), 31-44.

Brooks. M. (2003). Evaluating the "students experience": An approach to managing and enhancing quality in higher education. Journal of Hospitality, Leisure, Sport \& Tourism Education, 2(1), 17-26.

Carnell, E., \& Lodge, C. (2002). Supporting effective learning, London, UK: Paul Chapman.

Donnan, A., \& Carthy, R., (2011). Graduate employment and internships: Issues from the environmental sciences and sustainability sectors. The Institution of Environmental Sciences. Retrieved from https://www.the-ies.org/resour ces/graduate-employment-and

Fletcher-Brown, J., Knibbs, K., \& Middleton , K. (2015). Developing “employagility”: The 3Es case for live-client learning. Higher Education, Skills and Work-Based Learning, 5(2), 181-195.

Fox, D., \& Morrison, P. (2010). The introduction of a learning innovation to enhance the employability of event management students: An action research study. In Global events congress IV: Events and festivals research: State of the art, July 14-16, Leeds, UK.

Garlick, A. (2014). Experiential learning: Rationale, approaches and implications for practice in events management and hospitality courses. Investigations in University Teaching and Learning, 9. Retrieved from http:// repository.londonmet.ac.uk/326/1/InvestigationsInUni versityTeachingAndLearning\%20v9\%20p8-14.pdf

Getz, D., (2008). Event studies: Theory, research and policy for planned events (2nd ed.). Oxford, UK: Elsevier.

Goldblatt, J. J. (2000). A future for event management: The analysis of major trends impacting the emerging profession. Proceedings of the Conference on event evaluation, research and Education, July, Sydney, Australia.

Graham, J. J. (2003). Reflective portfolios for work based learning. Retrieved from http://www.recordingachieve ment.ac.uk/images/pdfs/case_studies/higher_education/ 100082.pdf

Hammersley, M., \& Atkinson, P. (1995). Ethnography. Principles in practice (2nd ed.). London, UK: Routledge.

Harrison, J. (2010). Professional development and the reflective practitioner. In S. Dymoke \& J. Harrison (Eds.),
Reflective teaching and learning (pp. 7-44). London, UK: SAGE.

Harvey, L. (2005). Embedding and integrating employability. New Directions for Institutional Research, 128, 13-28.

Hingley, V. (2008). Developing employability skill through employer engagement in Foundation degrees. In S. Graves \& A. Maher (Eds.), Developing graduate employability: Case studies in hospitality, leisure, sport and tourism (pp 1-16). London, UK: Threshold Press Ltd.

Hounsell, D. (2003). The evaluation of teaching. In H. Fry, S. Ketteridge, \& S. Marshall (Eds.), A handbook for teaching and learning in higher education (2nd ed). (pp. 200-212). Abington, UK: Routledge Falmer,

Hughes, K., Mylonas, A., \& Benckendorff. (2013), Student reflections on industry placement: Comparing four undergraduate work integrated learning streams. Asia Pacific Journal of Cooperative Education, 14(4), 265-279.

Jackson, D. (2013). The contribution of work-integrated learning to undergraduate employability skill outcome. Retrieved from http://www.apjce.org/files/APJCE_14 2_99_115.pdf

Jackson, N. (2010). The "wicked" problem of enhancing graduate impact. In P. Kemp \& R. Atfield (Eds.), Enhancing graduate impact in business and management, hospitality, leisure, sport and tourism (pp. V111-X111). London, UK: Threshold Press.

Kolb, A., \& Kolb, D. (2005). Learning styles and learning spaces: Enhancing experiential learning in higher education. Academy of Management Learning \& Education, 4(2), 193-212.

Kolb, D. A. (1984). Experiential learning: Experience as the source of learning. Upper Saddle River, NJ: Prentice Hall.

Lee K. M., Lee, M., \& Kim. H. J. (2009). A comparison of student and industry perceptions of the event management curriculum in Korea. Journal of Hospitality, Leisure, Sport \& Tourism Education, 8(2), 59-73.

Nixon, S., \& Dray, T. (2010). The world of work concept (WoW) and student curriculum experience. In P. Kemp \& R. Atfield, (Eds.), Enhancing graduate impact in business and management, hospitality, leisure, sport and tourism (pp. 32-39). London, UK: Threshold Press.

O’Donovan, B. (2010). Filing and pail or lighting a fire? The intellectual development of management graduates. The International Journal of Management Education, 9(1), $1-10$.

Patton, M. Q. (1990). Qualitative evaluation and research methods. London, UK: Sage.

Penger, S., Znidarsic, J., \& Dimovski, V. (2010). Experiential learning and management education: Empirical research and implications for practice in higher education in Slovenia. Paper presented at the EABR and ETLC Conference, Dublin, Ireland.

Pool, L., \& Sewell, P. (2007). The key to employability: Developing a practical model of graduate employability. Education + Training, 49(4), 277-289. 
Robertson, M., Junek, O., \& Lockstone-Binney, L. (2012). Is this for real? Authentic learning for the challenging events environment. Journal of Teaching in Travel \& Tourism, 12(3), 225-241.

Robson, C. (1993). Real world research: A resource for social scientists and practitioner-researchers. Oxford, UK: Blackwell.

Sealy, W. (2012). Embedding experiential learning in event management undergraduate degrees. Journal of Learning and Teaching, Paper 6.

Sealy, W., \& Wickens, E. (2008). The potential influence of mega sport media on the travel decision-making process and destination choice-The case of Portugal and Euro 2004. Journal of Travel and Tourism Marketing, 24(2/3), 127-137.

Silvers, J., Bowdin, G., O’Toole, W., \& Nelson, K. (2006). Towards an international event management body of knowledge (EMBOK). Event Management, 9(4), 185-198.

Stevenson, N. (2004). Practice paper: Redesigning seminars to enhance student learning and motivation. Paper presented at the Conference of the Association for Tourism in Higher Education, December 1-3, Buckinghamshire, UK.

Strauss, A., \& Corbin, J. (1990). Basics of qualitative research techniques and procedures for developing grounded theory. London, UK: Sage Publications.

Temple, P., Callender, C., Grove, I., \& Kersh, N. (2016). Managing the student experience in English higher education. Differing responses to market pressures. London Review of Education, 14(1), 33-46.

Tsai, C. Y. (2013). Employability, curriculum of higher vocational education and Human resource practice in tourism and hospitality. Journal of Sociological Research, 4(2), 336-348.

Wickens, E. (2002). The sacred and the profane: A tourist typology. Annals of Tourism Research, 29, 834-851.

Wickens, E., \& Forbes. A. (2004). In the own voices: Student experiences. Paper presented at the Conference of the Association for Tourism in Higher Education, December 1-3, Buckinghamshire, UK. 